\title{
COMO A LITERATURA PODE SER \\ FORMATIVA? SOBRE OS MODOS DE UMA \\ DIFERENCIAÇÃO MIMÉTICA DA RAZÃO
}

\author{
How can literature be formative? On the modes \\ of a mimetic differentiation of reason
}

RESUMO Que a literatura é importante para a formação é uma declaração geralmente bem aceita. Quando se pergunta pelos conceitos reguladores de literatura e de formação envolvidos, no entanto, as discussões, frequentemente, dão margem a desacordos fundamentais. Pretendo indicar que, quando se põe em questão o vínculo entre literatura e formação, se trata, a cada vez, de maneiras distintas de articular a relação entre o estético e o prático. A partir da atenção dada pela teoria crítica à dialética de razão em natureza, argumentarei a favor de uma potência formativa da literatura, remetendo-a à criação histórica de sentidos alternativos de mundo nos planos subjetivo, natural e social.

PALAVRAS-CHAVE: FORMAÇÃO; O ESTÉTICO; O PRÁTICO; TEORIA CRÍTICA; LITERATURA; RAZÃO

ABSTRACT Literature is usually conceived as an important factor to formation. It is also the case, however, that the use of the concepts 'literature' and 'formation' may give room to basic disagreements. In this paper, I would like to argue that when one thinks about the close relation between literature and formation, one is as the same time faced with basic differences involved in thinking the relation between the aesthetic and the practical realms. From the standpoint of Critical Theory's thoughts concerning the dialectics of reason and nature, I would claim that literature has a potential for formation which relies on its historical force of creation of alternative world meanings - to formulate news senses of subjective, natural and social worlds.

KeYwords: Formation; Aesthetic; Practical; Critical TheORY; LITERATURE; REASON.

\section{INTRODUÇÃO: FORMAÇÃO COMO CONCEITO FILOSÓFICO}

nicio este ensaio sobre a potência formativa da literatura pela hipótese que pretendo defender: só é possível pensar a literatura como experiência de formação a partir do momento em que se admite que os âmbitos da ação - isto é, do prático, que engloba a moral universalista e a ética da autorrealização (distinção

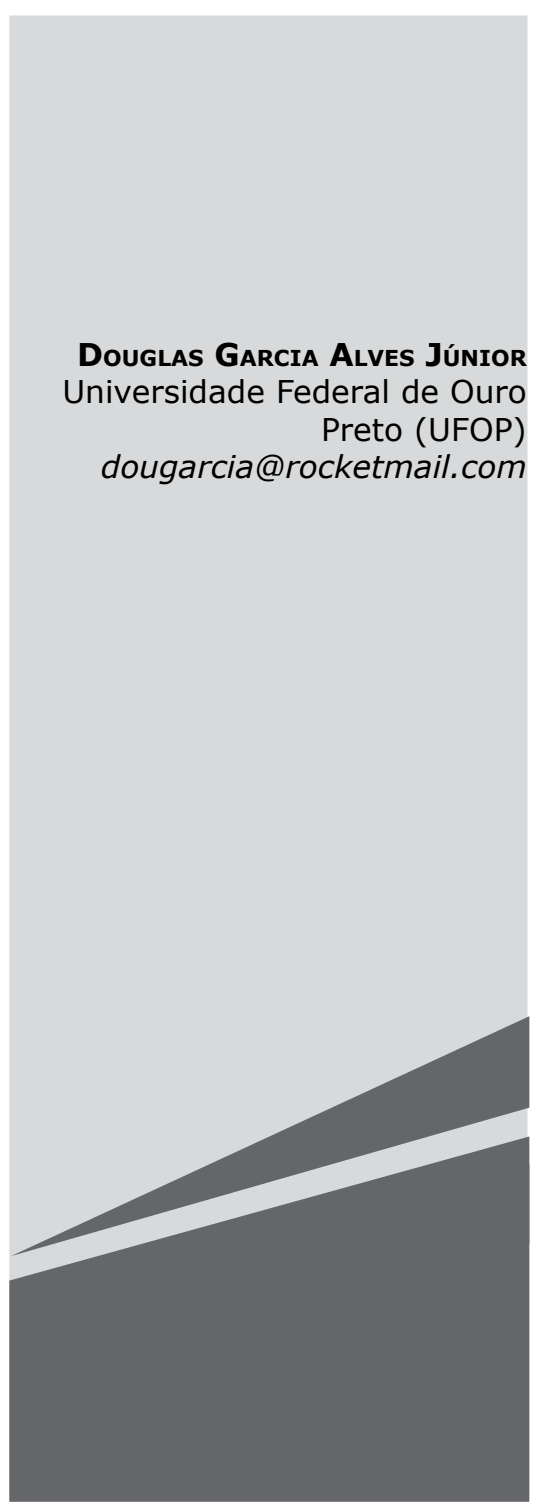


importante, como veremos a seguir) - e dos sentimentos - isto é, do estético, conquanto sejam esferas autônomas - são, como sabemos modernamente, domínios imbricados. Este não é um ponto de pouca importância para nenhum dos filósofos da teoria crítica, e veremos mais adiante por quê. Por ora, cabe assinalar uma resistência interna, filosófica, comum aos opositores da teoria crítica: fazer do estético um âmbito em que se jogam as mais altas destinações da razão - verdade, justiça, liberdade - é incumbi-lo de uma conta que ele não é capaz de pagar. Vejamos, em primeiro lugar, os termos dessa crítica e como enfrentá-la a partir de elementos da própria tradição filosófica. Espero que isso ajude a chegar a uma justificativa filosófica para a defesa da literatura como domínio de formação.

Quando se fala de formação, em termos filosóficos, alude-se a um desenvolvimento da razão, e está implicado no conceito de formação que se trata de um desenvolvimento diferenciador, auto-orientado e harmônico. Em outros termos, não basta falar aqui de simples aquisição de conhecimentos (por exemplo, geografia da América do Sul) e habilidades específicas (por exemplo, dirigir carros) com vistas a uma integração futura no mercado profissional. Do que trata a formação não é algo que possa ser descrito no contexto funcional das competências para o trabalho tal como este se encontra organizado na sociedade capitalista. Em outros termos, se o consideramos filosoficamente, o conceito de formação não é empírico, mas normativo. Ele pressupõe a autocompreensão moderna, que remonta ao século XVIII, de que a razão não se submete passivamente a nenhum esquema de coisas já dado, mas põe sempre em questão os princípios normativos das sociedades (na ética e na política), os procedimentos de instauração de conhecimentos confiáveis (na ciência) e as maneiras de estatuir consensos a respeito das qualidades específicas de obras de arte (na estética). Retomando os termos que introduzi há pouco: desde os últimos duzentos anos, só tem sentido falar em formação quando se assume a finalidade, tida como boa em si mesma, de desenvolvimento diferenciador, auto-orientado e harmônico da razão. E como a razão é um poder humano, trata-se do dever de promover esse desenvolvimento, não apenas para uns poucos beneficiários da divisão existente de poder econômico, social e político, mas para toda a humanidade. Cabe lembrar o que Marcuse (1978) mostrou em Razão e revolução e ao longo de toda a sua obra: a razão moderna tem vocação para intervir na vida real dos seres humanos; ela quer ser um estímulo e um aguilhão para a mudança nas formas de vida. A formação é um projeto social da razão moderna.

\section{A CENTRALIDADE dO ESTÉtico}

O ceticismo filosófico manifestado por alguns críticos ${ }^{1}$ de Adorno, de Marcuse e de Horkheimer, quando censuram o papel central atribuído ao estético na (auto)formação da razão moderna, na verdade é paralelo a uma desvalorização frequentemente operada pelo senso comum. Tudo se passa como se, no plano desse tipo de discurso filosófico, operasse inconscientemente (ou não) uma reverberação de três determinações do modo como o senso comum vê o domínio do estético: em primeiro lugar, o estético simplesmente não estaria no mesmo patamar da ciência e da moral (ou da religião); em segundo lugar, o plano do estético seria regido pelo consenso com relação àquilo que se pode chamar de beleza (concebida, no mais das vezes, em termos de harmonia da forma); em terceiro lugar, o estético seria afim a um plano espiritual, regido pelos movimentos do coração e os anseios da alma. Nessas três características que o senso comum vê no estético encontra-se a noção de que ele é a esfera da manifestação do autêntico sentimento individual, protegido da esfera material e dos embates da vida em sociedade. A desvalorização filosófica do estético, feita por alguns opositores da teoria crítica, acompanha essa visão do senso comum em todas essas determinações:

A este respeito, ver especialmente as críticas de Habermas (2002) e de Wellmer (1993), que são representativas desse tipo de oposição. 
ela vê no estético um domínio secundário em relação à ciência e à moral, e compreende-o a partir do quadro do consenso de opiniões discursivamente defensáveis quanto a tomadas de posição sobre a autenticidade da expressão de sentimentos sem ligação com a esfera material e com a crítica racional dos processos sociais. É como se o "caráter afirmativo da cultura", de que falava Marcuse (2006), se infiltrasse no discurso filosófico, como se fosse possível defender uma visão do estético ora como domínio do particular e irracional, ora como esfera integradora dos juízos de gosto, que deixa inalteradas as implicações normativas das esferas da ciência e da moral. A partir desses pressupostos restritivos, a formação da razão moderna não pode mais ser entendida como um projeto social.

É certo que a teoria crítica da sociedade apresenta outro entendimento do estético, muito mais afim ao conceito moderno de formação, que remonta a Kant e Hegel. Para a teoria crítica, trata-se de mostrar como o domínio do estético não é menos racional nem menos universal do que os domínios da ciência e da moral. O estético é o momento chave pelo qual os seres humanos experimentam sua ligação com a natureza, mediada por formas de percepção constituídas socialmente. Há um elemento histórico-transcendental na relação humana com a natureza: os seres humanos são sempre, também, parte da natureza com a qual se relacionam, e essa relação é sempre diferente. Marx (2004) registrou essa historicidade e transcendentalidade da natureza no conceito de necessidade. Adorno falou disso em termos de "história natural" (1973), e, mais adiante, na Dialética do esclarecimento, escrita com Horkheimer (1985, p. 44), de "natureza no sujeito". Se a ciência é o modo pelo qual a razão instaura um trato objetivante e instrumental com a natureza, o estético é o modo pelo qual a razão constrói uma relação subjetivante e hermenêutica com a natureza: ela passa a ter sentido, independentemente do uso que possamos dela extrair. Há uma passagem de Horkheimer que fala dessas modalidades distintas da relação humana com a natureza:
Outrora era o esforço da arte, da literatura e da filosofia para expressar o significado das coisas e da vida, para ser a voz de tudo que é mudo, para dotar a natureza de um órgão que manifestasse os seus sofrimentos, ou, pode-se dizer, chamar a realidade pelo seu nome legítimo. Hoje a língua da natureza foi arrancada. Outrora pensava-se que cada expressão, palavra, grito ou gesto tivesse um significado intrínseco; hoje é apenas um incidente. Por um lado, a natureza foi despojada de todo valor ou significado intrínseco. Por outro, o homem foi despojado de todos os objetivos, exceto o de autoconservação. (HORKHEIMER, 2002, p. 105).

A razão subjetiva instrumentalizada ou louva a natureza como pura vitalidade ou a deprecia como força bruta, em vez de considerá-la como um texto a ser interpretado pela filosofia que, se for corretamente lido, revelará uma história de sofrimento infinito. Sem cometer a falácia de igualar natureza e razão, a humanidade deve tentar conciliá-las. (HORKHEIMER, 2002, p. 128).

A teoria crítica é marcada pelo propósito de trazer à razão o seu momento de natureza, registrado no sensorium humano na qualidade de experiência estética da variedade e independência do mundo sensível.

\section{SENTIR E AGIR}

A afinidade humana com a natureza só pode ser descoberta pela razão. E ela só pode ser nomeada a partir de uma linguagem cujos termos são cunhados em uma determinada sociedade. Nesse sentido, o domínio do estético é aquele em que essa afinidade da razão com a natureza é posta em primeiro plano. Mais do que isso, ela é assumida como constituidora das relações dos seres humanos en- 
tre si. Estamos falando de uma constituição mimética da razão. Adorno concebeu essa dialética de razão e mimesis a partir de uma revisão da doutrina kantiana do transcendental. Em Kant (1995), o domínio do estético é mimético e racional, isto é, dotado de universalidade - ainda que não a do conceito, mas a do juízo estético, que é uma universalidade subjetiva, referente ao modo como as faculdades do ânimo são afetadas por objetos do mundo sensível, em termos de prazer comunicável e hipoteticamente atribuível aos outros membros da comunidade humana. Por outro lado, em Kant (1994) o domínio do prático, do moral, conquanto seja racional, não é mimético: a lei moral, que funda a autonomia do sujeito agente, é completamente inteligível, independentemente da contingência das afecções e, até mesmo, da constituição da espécie humana. A doutrina kantiana separa conclusivamente, de um lado, os domínios do sentir e atribuir significado com-os-outros aos fenômenos da natureza, o sentir estético, e, de outro, o agir moral - que não é, em Kant, constituído com-os outros, como bem notou Hannah Arendt (1993), em suas Lições sobre a filosofia política de Kant. Pode-se perceber, quando se examina os termos da metacrítica adorniana de Kant, a razão pela qual a mais estrita e precisa separação dos domínios do estético e do prático, a saber, aquela estabelecida pela demarcação dos domínios da Crítica da faculdade do juízo (KANT, 1995) e da Crítica da razão prática (KANT, 1994) só pôde lograr-se por meio de um reconhecimento da constituição de certo regime de racionalidade (o dos juízos reflexionantes) a partir da experiência mimética da afinidade de sujeito e natureza - ainda que à custa de um bloqueio do exame de suas possibilidades. Pensar a relação entre o estético e o moral a partir do transcendental implica excluir qualquer relação interna entre natureza, sociedade e formação das faculdades do agir e do atribuir sentido ao mundo - não só ao mundo natural, mas aos mundos subjetivo e social.

A teoria crítica detecta no estético a densidade histórica das relações humanas com a natureza. "O gosto é o mais fiel sismógrafo da experiência histórica”, escreveu Adorno em Minima moralia (1992, p. 127). Aqui se torna mais claro porque a teoria transcendental da moralidade tem dificuldade em assentar em termos persuasivos a gênese da motivação para a ação moral. Com efeito, a noção de respeito como sentimento inteligível, erigida por Kant (1994, p. 89) em motivo moral por excelência, parece deixar flancos para todo tipo de objeções, como a que Nietzsche mais tarde formulará: como pode um sentimento ter origem puramente inteligível? "O 'puro espírito' é pura tolice” (NIETZSCHE, 2007, p. 20). A falta de percepção da dialética histórica das motivações para a ação moral incide decisivamente sobre a teoria do ético, isto é, afeta a intelecção do domínio das relações dos sujeitos com suas expectativas de realização. Isso é registrado de forma exemplar em John Stuart Mill. Cito sua Autobiografia:

Foi no outono de 1826 . Eu me encontrava em um estado de apatia, ao qual todas as pessoas estão, ocasionalmente, sujeitas: insensível aos estímulos de prazer ou alegria, um desses estados de ânimo em que o outrora agradável torna-se insípido e indiferente [... ] Nesse estado de espírito ocorreu-me dirigir a mim mesmo a seguinte pergunta: 'Suponha que todas as tuas metas na vida fossem realizadas, que todas as transformações que tu persegues nas instituições e opiniões pudessem ser efetuadas neste instante mesmo: seria isto motivo de grande alegria e felicidade para ti?' E minha consciência, sem poder se reprimir, respondeu: 'Não!' Meu coração então se abateu: todo o fundamento sobre o qual eu erguera a minha vida havia ruído. Toda minha felicidade consistia na permanente busca daquela meta [a reforma das instituições segundo o 'princípio da utilidade'], e esta meta já não me 
atraía. Como então os meios poderiam me interessar? Parecia-me que não restava mais nada por que viver. (2007, p. 124).

Mill descobre não possuir qualquer motivação ética, isto é, de realização pessoal, para a ação em termos de um princípio moral intersubjetivo. Ele mesmo detecta a causa dessa deficiência: a falta de um genuíno sentimento de interesse - de simpatia, para usar o termo que ele emprega - pelos destinos de outros seres humanos tomados individualmente - e não considerados sob a abstração embutida no princípio do cálculo racional da maior felicidade da humanidade (MILL, 2007, p. 127ss). Cito Mill:

Da verdade, disto eu estava convencido, mas saber que um sentimento me tornaria feliz caso eu o tivesse não produzia em mim o sentimento. Minha educação, pensava eu, havia fracassado no momento de criar esses sentimentos... não me comprazia nem na virtude, nem no bem geral, nem tampouco em nenhuma outra coisa. (MILL, 2007, p. 128).

Eu havia aprendido, agora por experiência, que as sensibilidades passivas precisam ser cultivadas tanto quanto as capacidades ativas, e que necessitam ser alimentadas e enriquecidas, além de guiadas... A manutenção de um equilíbrio entre as faculdades parecia-me agora de primeira importância. O cultivo dos sentimentos se converteu em um dos pontos primordiais de meu credo ético e filosófico. (MILL, 2007, p. 131).

O "cultivo dos sentimentos", que Mill vem a reconhecer como fonte necessária da motivação para a ação moral, remete àquilo que é possível conceber como o momento mimético, pré-conceptual da experiência do prático (incluídos aí o moral e o ético). Não é à toa que Mill atribui a recuperação de sua crise pessoal de 1826 à frequentação da música e da poesia, que o remeteram aos sentimentos comuns dos outros seres humanos e à beleza, significativa em si mesma, da natureza (MILL, 2007, p. 132-136). É no âmbito do que a teoria crítica chama de natureza interna que se dá a permeabilidade entre o sentir e o agir, o estético e o moral.

\section{A RELAÇÃo ENTRE O ESTÉTICO E O MORAL}

Se Mill tem o mérito de apontar para a questão da gênese empírica da motivação prática, ético-moral, é a Schiller que devemos recorrer para pensar mais produtivamente a passagem entre os âmbitos do prático e do estético. Deve-se a ele o mais refinado diagnóstico daquilo que Marx registraria mais tarde em termos dos processos de reprodução material das sociedades modernas. Cito Schiller, na Carta VI de A educação estética do homem em uma série de cartas (2002):

Rompeu-se a unidade interior da natureza humana e uma luta funesta separou suas forças harmoniosas. [...] A natureza de pólipo dos Estados gregos, onde cada indivíduo gozava uma vida independente e podia, quando necessário, elevar-se à totalidade, deu lugar a uma engenhosa engrenagem cuja vida mecânica, em sua totalidade, é formada pela composição de infinitas partículas sem vida. [...] Eternamente acorrentado a um pequeno fragmento do todo, o homem só pode formar-se enquanto fragmento; ouvindo eternamente o mesmo ruído monótono da roda que ele aciona, não desenvolve a harmonia de seu ser e, em lugar de imprimir a humanidade em sua natureza, torna-se mera reprodução de sua ocupação, de sua ciência. (SCHILLER, 2002, p. 37). 
Em que pese a idealização da polis grega, Schiller toca em um aspecto fundamental que estará presente em todos os diagnósticos materialistas da reificação, de Marx a Adorno, passando por Lukács: a exposição da dupla face, objetiva e subjetiva, do alheamento humano em relação às suas forças de sentir e de agir. Schiller detecta, já no final do século XVIII, a sua face objetiva, ligada à organização social do trabalho, na qual imperam a atomização de processos e o rompimento do sentido do todo das operações técnicas a ele ligadas, de um lado, e à especialização burocrática da atividade política, cada vez mais restrita a técnicos profissionais, de outro. Ao mesmo tempo, Schiller percebe a dimensão subjetiva do processo que se instala sob a forma de uma cisão que passa a ser determinante: aquela entre as faculdades racionais ligadas à instrumentalização do mundo natural e as faculdades sensíveis, que respondem pela afinidade subjetiva com a natureza e entre os seres humanos. Assim, a delimitação do impulso lúdico, de jogo, como faculdade humana básica, responde a uma necessidade interna do pensamento schilleriano: a de superar as dicotomias estritas entre razão e sensibilidade, determinação do conceito e recepção do sentimento, atividade intelectual e passividade da sensação, forma e matéria, transcendental e empírico - desígnio que advém de sua frequentação da Crítica da faculdade do juízo, de Kant (1995). Em Schiller, a concepção de formação como um desenvolvimento diferenciador, auto-orientado e harmônico das faculdades humanas é posta, pela primeira vez, como propósito inserido em uma dialética social. A formação da humanidade, tornada possível pelo potencial integrador do impulso lúdico, só é pensável como formação da sociabilidade.

\section{BLOQUEIOS NORMATIVOS CONTEMPORÂNEOS}

Quando se considera o estádio atual das demandas e das discussões pedagógicas, mal se pode evitar a pergunta: por que esse conceito normativo e filosófico de formação seria obrigatório para nós? Pode-se sempre inverter a pergunta: por que o horizonte pedagógico das sociedades em que vivemos seria obrigatório para nós? As defesas do status quo, baseadas no peso da tradição, ou na força de convicções metafísicas, não possuem o estatuto racional exigido para a justificação normativa de práticas que transcorrem em sociedades abertas à discussão de seus fundamentos normativos. Aqui não se pode evitar a suspeita de que as discussões normativas sobre a educação não avançaram na mesma extensão alcançada em outros domínios da sociabilidade. Tudo se passa como se a dinâmica de integração imposta pelos movimentos do capital detivesse a última palavra. A força de inércia de práticas educativas destinadas à instrução funcional passa a operar como uma justificação empírica para o sistema. Nesse cenário, demandas advindas de uma adequação do processo educacional às necessidades de uma sociabilidade renovada por outros imperativos que não os do uso instrumental da natureza conforme aos esquemas cognitivos da ciência e da técnica passam a ser postas em segundo plano, quando não são sequer discutidas. O conceito de formação passa a ser visto como o resíduo indesejável de uma sociedade orientada para a otimização técnica do metabolismo com a natureza. Marcuse (1964) forneceu uma descrição aguda desse tipo de orientação técnica da sociedade em One-dimensional man: Studies in the ideology of advanced industrial society ( $O$ homem unidimensional).

\section{A LITERATURA EM UM MUNDO UNIDIMENSIONAL}

O que a literatura teria a nos oferecer em um ambiente como esse? Como poderia a literatura ser tomada como uma fonte racional capaz de ser formativa dos potenciais de transformação das relações humanas com a natureza? Teria a literatura o poder de ativar processos de desenvolvimento de uma autocompreensão racional do lugar dos sujeitos humanos no mundo, nos âmbitos, não só estético, mas também prático, nos domínios 
do ético e do moral?

Quem se põe a pensar em literatura e formação a partir do horizonte intelectual da teoria crítica depara-se com dois problemas, a princípio. Coube a Adorno (1993), na Teoria estética, a sua formulação mais direta. Em primeiro lugar, nenhum dos conceitos estéticos fundamentais pode ser tomado como invariante, de modo transcendental ou substancialista - nem mesmo o de forma, ele acrescenta, para tornar mais clara a sua posição. Daí se segue que não há como definir o que é literatura com um conceito fixo - ela não é inteligível como um conjunto de propriedades essenciais que, uma vez conhecidas, possam ser usadas como critério de identificação de "literariedade", isto é, daquilo que é e do que não é literário. O outro problema que ronda a literatura é formulado por Adorno da seguinte maneira: entende erradamente a obra de arte, e por extensão, a literatura, quem a entende a partir de um ponto de vista exclusivamente estético. A formulação aguda dos dois problemas tem o poder de surpreender aqueles que tomam Adorno por um defensor da autonomia absoluta das obras de arte, autonomia que supostamente privilegiaria sua feição hermética, formalista e antissocial. Mencionei aqui a palavra "problema" no sentido de questão produtiva, que aponta para a complexidade dos objetos, e a dificuldade de sua correta intelecção. Alargando a complexidade dessas questões, Adorno pretende que as obras de arte veiculem um "conteúdo de verdade", em sentido forte, isto é, que elas deem a ver aspectos fundamentais da dinâmica histórica, social e subjetiva, por meio de sua composição interna. É como se a obra de arte bem realizada pudesse fornecer um modelo universal-concreto de subjetividade: a identidade que ela arranca das tensões do existente é um modelo de subjetivação bem-sucedida. Nesse sentido, cada leitor, ouvinte, ou espectador repetiria, no contato com a obra, os estágios da formação que a própria obra percorreu. Assim, retomando os três problemas aludidos acima, trata-se, para o sujeito estético, de realizar um trabalho tri- plo: compreender em que medida aquela obra específica participa do literário (ou do musical, ou do pictórico); reconstituir o quadro de tensões sociais, políticas e culturais ao qual ela historicamente reage; julgar a força de sua realização, o modo como ela transforma aquelas tensões em lei formal estética, isto é, em que medida há ali uma "verdade" a respeito da condição do presente que não poderia ser exposta de outra forma, nem por outros meios.

O problema com a literatura, do ponto de vista da indústria cultural, é que ela não é espetacular - e aqui uso a palavra "problema" no sentido comum, de mau funcionamento de um mecanismo destinado a uma eficácia especificável. Daí a profusão das adaptações cinematográficas, das feiras de livros em que celebridades posam para selfies com seus fãs e dos prêmios de literatura noticiados à maneira de Hollywood. Nesse cenário, pretender que o leitor-consumidor da espetacularização do universo literário atual tenha em mente as questões postas à literatura por Adorno pode soar irrealista. No entanto, no interesse do conceito normativo de formação, do que se trata é de pensar a literatura como espaço de articulação de um sentido de transcendência do existente, do que Adorno chamou de "experiência do negativo". Se a literatura é chamada a preencher a destinação de uma eficácia especificável - o desempenho em testes cognitivos, a competência na comunicação empresarial, a exibição de sinais exteriores de distinção -, ela deixa de ser um problema, no sentido instrumental, mas também deixa de evocar o sentido formativo das obras literárias, inteligíveis como dinâmicas de subjetividade autocontidas, no plano da forma, e socialmente mediadas, no plano da gênese.

\section{A POTÊNCIA DA LITERATURA}

Seria possível pensar em literatura, hoje, em analogia com a argumentação desenvolvida por Horkheimer (1990), em Observações sobre ciência e crise, a respeito da dialética de forças produtivas e meios de produção. Nessa 
perspectiva, considerar-se-ia o uso espetacularizado e instrumental da literatura em termos de sua inserção no universo dos meios de produção, isto é, daquilo que é requerido para a reprodução material e simbólica da sociedade. De modo análogo à ciência, considerada no texto de Horkheimer, a literatura é um fenômeno social que gera renda, empregos, cria um mercado produtor, distribuidor e consumidor de produtos, além de comunicar-se com as áreas industrializadas do cinema e da publicidade. Por outro lado, a partir dessa analogia, poder-se-ia considerar a literatura como força produtiva, isto é, como elemento de desenvolvimento e transformação qualitativa da relação social humana com a natureza, seja com o meio ambiente externo, seja com a natureza interna, constituída por inclinações afetivas, tendências pulsionais e necessidades de autorrealização. Nesse sentido, caberia, ainda, apostar na literatura como potência de formação. Pensar a literatura como parte das forças produtivas humanas implica considerá-la a partir de um conceito alargado de subjetividade, referido, não às categorias de intenção autoral, vivência interior e autenticidade da expressão de sentimentos privados, mas à intersubjetividade implícita nas formações culturais e sociais. Trata-se do que Adorno (2003), em sua Palestra sobre lírica e sociedade, chamou de corrente subterrânea da lírica, formada por um sujeito coletivo que busca expressão com os meios da linguagem. Tomar a literatura como força produtiva é lembrar que o estético é social. Antes de ser posto na forma de obras de arte, o estético vive na imanência do trabalho humano, na relação corporal e sensorial envolvida na transformação da natureza segundo as necessidades humanas. É a Marx que se deve a compreensão mais clara desse processo, nos Manuscritos econômico-filosóficos (2004): o alimento toma a forma humana da comida, o som toma a forma da música, o mineral toma a forma da beleza que o olho humano enxerga na natureza. Há sempre flutuação e complexidade nesse trabalho do sensorium humano; ele nunca é meramente privado e "desligado" da história, mas sempre formado de acordo com o estágio social das forças produtivas. Como Marx escreveu naquele texto: "a formação dos cinco sentidos é um trabalho de toda a história do mundo" (MARX, 2004, p. 110). Isso significa que os âmbitos sociais do trabalho e do estético contêm sempre um grau de opacidade, de resistência à integração às malhas do discurso público sobre razões para justificar normas de ação. Isso ocorre porque há uma distância, da ordem do que Adorno chamou de o não idêntico, entre aquilo que podemos justificar racionalmente em termos de princípios comuns e aquilo que nos leva, na prática, a agir, segundo a compreensão de nossas necessidades como seres de natureza, ligados conflituosamente uns aos outros pela corporeidade e pelo trabalho. Ignorar isso é ignorar o conflito social como realidade humana.

\section{LITERATURA E SENSIBILIDADE}

É esse o elemento que cabe à literatura: não tanto representar como expor, pôr em questão, expressar. São conhecidas as caracterizações de Adorno, na Teoria estética, de que a "a arte é antítese social da sociedade" e "mimeses da reificação" (1993, p. 19, p. 259). A arte lida com uma intersubjetividade presente $e$ virtual: presente na forma reificada das relações de trabalho e de sensibilidade contemporâneas que ela mimetiza; virtual na forma do elemento irredutível de sentido, alcançado por seu trabalho formal, pelo qual ela se destaca da mera cópia do existente. Ao invés de adequação a um valor transcendente (o Bem, a Verdade, a Beleza) ou expressão de uma suposta "natureza humana", a literatura testemunha o desajuste produtivo dos sujeitos humanos em relação a si mesmos e à natureza. Só é possível falar de formação daquilo que não está consumado desde o início. Os aspectos estético e o prático da formação cruzam-se (sem se cofundir) no elemento intersubjetivo da experiência mimética de pertencimento humano à natureza. A literatura é esteticamente performativa, no sentido de que é dirigida à comunidade virtual dos leitores, aos quais afeta no âmbito do prazer e do desprazer que estes 
obtêm com a representação linguística dos mundos subjetivo, social e natural. Nos termos da estética de Adorno, a literatura é aparência, e a relação estética que os leitores têm com a literatura não afeta imediatamente o seu agir. Há na experiência literária uma suspensão dos motivos da ação: assim como o espectador do teatro não se levanta para matar o ator que interpreta o vilão no palco, o leitor não sai à rua para interagir com os personagens com os quais dialoga imaginariamente na leitura do livro. É possível pensar, no entanto, que há uma performatividade diferida, mediada, da experiência com a literatura. Será possível ler uma obra literária significativa sem que qualquer tipo de atitude prática venha a formar-se? Falo de atitude, pois não se trata de ação imediata, mas de uma sensibilidade para os motivos de ação que vêm dos outros, distantes e diferentes de "nós". Trata-se de direção contrária à atitude que Adorno enxergou na "frieza burguesa”, em Educação após Auschwitz (1995, p. 133). É possível pensar que a literatura pode ser praticamente performativa. No plano prático-moral, ela teria o poder de afetar os sujeitos no nível de suas motivações para a ação em conjunto, isto é, ela poderia atuar favoravelmente, no sentido de que eles possam se tomar como membros de uma comunidade moral ideal, em que expectativas de reciprocidade não violenta sejam possíveis e racionais. No plano prático-ético, a literatura poderia afetar os sujeitos no nível de suas motivações e expectativas de realização pessoal de uma "boa vida”, isto é, ela poderia atuar favoravelmente no sentido de que eles possam se tomar como autores de seu plano de vida, especialmente no que se refere à assunção autônoma de finalidades decisivas para a configuração de sua identidade pessoal.

\section{CONCLUSÃO: LITERATURA COMO INVENÇÃO DE MUNDOS ALTERNATIVOS}

Evoquei sucessivamente Horkheimer, Stuart Mill e Schiller para mostrar como se constituem as demandas humanas de sentido para a relação com a natureza (estética), a relação a si (ética) e a relação com o mun- do social (moral). O que a literatura teria a ver com tudo isto? E como ela poderia ser formativa? O que se segue são apenas fragmentos indicativos. Em primeiro lugar, a literatura não é algo que se possa contar como um dado invariante, e, assim, não está garantido o seu lugar na experiência humana futura. Por outro lado, a literatura parece vir ao encontro da capacidade humana de agir por meio da linguagem. Seu poder diferenciador não pode ser subestimado - as reflexões de Hannah Arendt (2004, p. 188-200), em A condição humana, são valiosas a esse respeito. Enquanto os seres humanos considerarem importante interpelarem-se uns aos outros a respeito do sentido das ações que praticam, das coisas que fabricam e do mundo natural em que vivem, a literatura talvez conserve um valor independente. A Poética, de Aristóteles (1993), estabeleceu a confiança ocidental na literatura, com a afirmativa de que "o imitar é congênito ao homem", ${ }^{2}$ bem como o seu objeto privilegiado, com a noção de que a tragédia é "imitação de uma ação". 3 A esse respeito, muito poderia ser discutido. Talvez pudéssemos ao menos reter a ideia de que a literatura, em sua dimensão de interpelação, é um domínio das práticas culturais - que já existiram antes de nós e que ainda existem hoje - que se orientam pela ideia de confronto linguístico do "eu" com o "tu", do "nós" com os "eles" - até mesmo do "eu" com o "si", e do "nós" com o "isso" do animal, do inorgânico e do inteligível (seja este concebido como linguagem, como razão, ou como espírito). O ponto de partida da literatura já

\footnotetext{
"Ao que parece duas causas, e ambas naturais, geraram a poesia. $O$ imitar é congênito no homem (e nisso difere dos outros viventes, pois, de todos, ele é o mais imitador, e por imitação aprende as primeiras noções), e os homens se comprazem no imitado" (ARISTÓTELES, 1993, p. 27).

3 “É pois a tragédia imitação de uma ação de caráter elevado, completa e de certa extensão, em linguagem ornamentada e com as várias espécies de ornamento distribuídas pelas diversas partes do drama, imitação que se efetua não por narrativa, mas mediante atores, e que, suscitando o terror e a piedade, tem por efeito a purificação dessas emoções" (ARISTÓTELES, 1993, p. 37).
} 
implica um descentramento da posição subjetiva, um experimento com a assunção de perspectivas de segunda e de terceira pessoas. Nesse sentido, há razões para confiar que a literatura permanecerá, na bela formulação de Adorno sobre o belo natural, o "vestígio do não-idêntico nas coisas sob o sortilégio da identidade universal" (1993, p. 90).

\section{REFERÊNCIAS}

ADORNO, T. W. Die Idee der Naturgeschichte. In: ADORNO, T. W. Gesammelte Schriften 1: Philosophische Frühschriften. Frankfurt: Suhrkamp, 1973.

ADORNO, T. W. Minima moralia: reflexões a partir da vida danificada. São Paulo: Ática, 1992. ADORNO, T. W. Teoria estética. Lisboa: Edições 70, 1993.

ADORNO, T. W. Educação após Auschwitz. In: ADORNO, T. W. Educação e emancipação. São Paulo: Paz e Terra, 1995.

ADORNO, T. W. Palestra sobre lírica e sociedade. In: ADORNO, T. W. Notas de literatura I. São Paulo: Editora 34, 2003.

ADORNO, T. W.; HORKHEIMER, M. Dialética do esclarecimento. Rio de Janeiro: Jorge Zahar, 1985. ARENDT, H. Lições sobre a filosofia política de Kant. Rio de Janeiro: Relume Dumará, 1993.

ARENDT, H. A condição humana. Rio de Janeiro: Forense Universitária, 2004.

ARISTÓTELES. Poética. São Paulo: Ars Poética, 1993.

HABERMAS, J. O entrelaçamento de mito e esclarecimento: Horkheimer e Adorno. In: HABERMAS, J. $O$ discurso filosófico da modernidade. São Paulo: Martins Fontes, 2002.

HORKHEIMER, M. Observações sobre ciência e crise. In: HORKHEIMER, M. Teoria crítica I. São Paulo: Perspectiva, 1990.

HORKHEIMER, M. Eclipse da razão. São Paulo: Centauro, 2002.

KANT, I. Crítica da razão prática. Lisboa: Edições 70, 1994.

KANT, I. Crítica da faculdade do juízo. Rio de Janeiro: Forense Universitária, 1995.

MARCUSE, H. One-dimensional man: Studies in the ideology of advanced industrial society. Boston: Beacon, 1964.

MARCUSE, H. Razão e revolução: Hegel e o advento da teoria social. Rio de Janeiro: Paz e Terra, 1978. MARCUSE, H. Sobre o caráter afirmativo da cultura. In: MARCUSE, H. Cultura e sociedade. São Paulo: Paz e Terra, 2006. v. 1.

MARX, K. Manuscritos econômico-filosóficos. São Paulo: Boitempo, 2004.

MILL, J. S. Autobiografia. São Paulo: Iluminuras, 2007.

NIETZSCHE, F. O anticristo: maldição ao cristianismo. São Paulo: Companhia das Letras, 2007. SCHILLER, F. A educação estética do homem em uma série de cartas. São Paulo: lluminuras, 2002. WELLMER, A. Truth, semblance, reconciliation: Adorno's aesthetic redemption of modernity. In: WELLMER, A. The persistence of modernity: essays on aesthetics, ethics and postmodernism. Cambridge: MIT, 1993.

DADOS AUTORAIS:

Douglas Garcia Alves Júnior: Doutor em Filosofia pela UFMG. Professor Associado do Departamento de Filosofia da Universidade Federal de Ouro Preto (UFOP).

Recebido: 25/02/2015

Aprovado: 08/05/2015 